\title{
Synergistic Effects in Stress Corrosion Cracking of Glass Reinforced Polymer Composites
}

\author{
Euripides Solis-Ramos and Maciej Kumosa ${ }^{a}$ \\ National Science Foundation Industry/University Cooperative Research Center for \\ Novel High Voltage/Temperature Materials and Structures University of Denver; \\ 2390 S. York St. Denver CO 80210, USA. \\ ${ }^{a}$ Corresponding author, Tel.: + 01303 871-3807; fax: + 01303 871-4450 \\ E-mail addresses: maciej.kumosa@du.edu (M. Kumosa), esolisra@du.edu (E. Solis- \\ Ramos).
}

\begin{abstract}
Synergistic effects of nitric acid exposure, elevated temperature, applied flexural stress and time were examined in the Stress Corrosion Cracking (SCC) of widely used unidirectional Glass Reinforced Polymer (GRP) composites. The composites were composed of two different E-CR glass fibers with a vinylester-epoxy resin as the matrix with E-glass fibers in the same matrix used for a baseline comparison. SCC damage, as measured by the number of fiber cracks, amount of metallic ion leaching from the fibers, and the reduction of residual flexural strength and stiffness properties of the composites, affected the composites differently depending on their composition. As expected, the E-CR composites greatly outperformed the E-glass composites under all conditions. Long term exposure of the E-CR composites did not greatly increase the amount of stress corrosion fiber damage; instead, interface issues and matrix decomposition led to reduced mechanical properties over extended periods of time. The synergistic effect of the combined testing conditions was found to be much stronger in the E-glass than the E-CR glass composites.
\end{abstract}


Keywords: Synergistic degradation, Stress Corrosion Cracking, E-CR glass fiber, Glass Reinforced Polymer Composite.

\section{Introduction}

Stress corrosion cracking (SCC) in glass reinforced polymer (GRP) composites has been investigated for many years [1-22]. Despite numerous contributions, many aspects of this very interesting failure process have not been thoroughly investigated, especially under combined conditions that simulate synergistic effects. It is well know that boron free E-CR glass fibers exhibit a much higher resistance to SCC than traditional E-glass fibers $[1,3,5,6,9,13,14,23-29]$. This effect has been widely reported by many investigators over the last 30 years. It has not been shown, however, how the chemical composition of E-CR fibers coming from different manufacturers could affect their resistance to SCC under extreme conditions.

SCC in GRP with E-glass fibers and a large family of polymer resins can be easily achieved in almost any corrosive environment in the presence of free hydrogen ions with and without externally applied mechanical tensile loads. It has been shown that the process depends on composite quality $[1,2,11]$, resin type $[9,12]$, type of acid $[7,15$, $18,21,30]$, magnitudes of mechanical loads $[8,10,28]$, acid concentrations, temperature [6, 31, 32], artificially introduced damage such as, for example, sandblasting $[13,14]$ and many other less important factors $[19,33-35]$. It has also been 
shown that SCC can be created in a variety of GRP samples such as beams [20], plates $[2,6,9-12,14,30]$, rods $[8,13,16,17,19,34]$, tubes $[1,36]$ and others. In most cases GRPs can be ranked for their resistance to SCC by their time to failure, which will depend on environmental conditions and the type and quality of a composite. Other methods such as acoustic emission $[8,9,11-14,16,17,37]$ have been used in the past to monitor the process and rank different GRPs with significantly different resistance to SCC. However, if the quality of composites is high, and if the composites are based on E-CR fibers, detecting any meaningful differences between their resistances to SCC can be very difficult [37].

In this research we have attempted to make new contributions in the area of SCC of GRPs for various applications. In particular, we have examined how certain widely used GRPs could behave under high voltage (HV) transmission line conditions involving strong nitric acid up to $0.5 \mathrm{~N}$, elevated temperatures up to $80^{\circ} \mathrm{C}$ and mechanical loads up to $22 \%$ of ultimate flexural strengths. Nitric acid was selected as the primary source of free hydrogen ions due to its presence on transmission lines, already reported in our previous papers $[8,9,11-14,16,17]$. It can be expected, however, that most of our observations and conclusions reported in this work are applicable to other similar GRP composite systems tested in significantly different corrosive environments. 


\section{Materials and Experimental Procedures}

\subsection{Materials}

Three different GRPs based on E-glass and E-CR glass fibers in a vinylester-epoxy resin were investigated in this study. The composites were fabricated by pultrusion by a composite manufacturer using one E-glass and two different E-CR-glass (labeled as ECR 1 and E-CR 2) fibers. The origins of the polymer matrix and the fibers as well as the name of the pultruder are proprietary information. Since the fibers came from three different glass suppliers, their sizings were most likely also different.

\subsection{Surface condition and fiber characterization}

The overall surface conditions of the composites were analyzed using a JEOL model JSM 5800 LV Scanning Electron Microscope (SEM) and an optical Olympus BX51M microscope $(\mathrm{OM})$. The average fiber diameters in the composites were determined by performing a series of measurements on randomly selected SEM cross-sectional images under the same magnification and by selecting approximately 250 fibers for each composite. Measurements of exposed fiber areas in the surface of the composites before aging were carried out using the optical microscope. The measurements were performed on ninety optical images, which were taken from six different specimens for each composite type. Percentages of exposed fiber areas were evaluated by image transformation using color separation by a commercial image analysis software. 
The elemental analysis of the fibers was conducted independently using the JEOL JSM 58000 LV with an EDS Oxford Instruments Aztec X-act, and by an electron microprobe, JEOL JXA-8600. The instruments were used to perform 6 point microprobe analyses on each glass sample. Ka radiation of elements was detected simultaneously using a total of 4 wavelength-dispersive spectrometers. The probe was operated at $20 \mathrm{kV}$ using $5 \mu \mathrm{m}$ probe diameter, and the Geller dQuant spectrometer program was used to compute the nominal matrix correction between the element and standard composition.

\subsection{Three point bend and stress corrosion testing}

Flexural strength and modulus of the composites were measured before and after stress corrosion testing under three point bending using an MTS 858 load frame following ASTM D790 [38]. All tested specimens were $3.2 \mathrm{~mm}$ thick, $12.7 \mathrm{~mm}$ wide and $63.5 \mathrm{~mm}$ long. For the stress corrosion testing, self-loaded four point loading fixtures were used (Figure 1). The fixtures were custom built following ASTM D6272-10 [39].
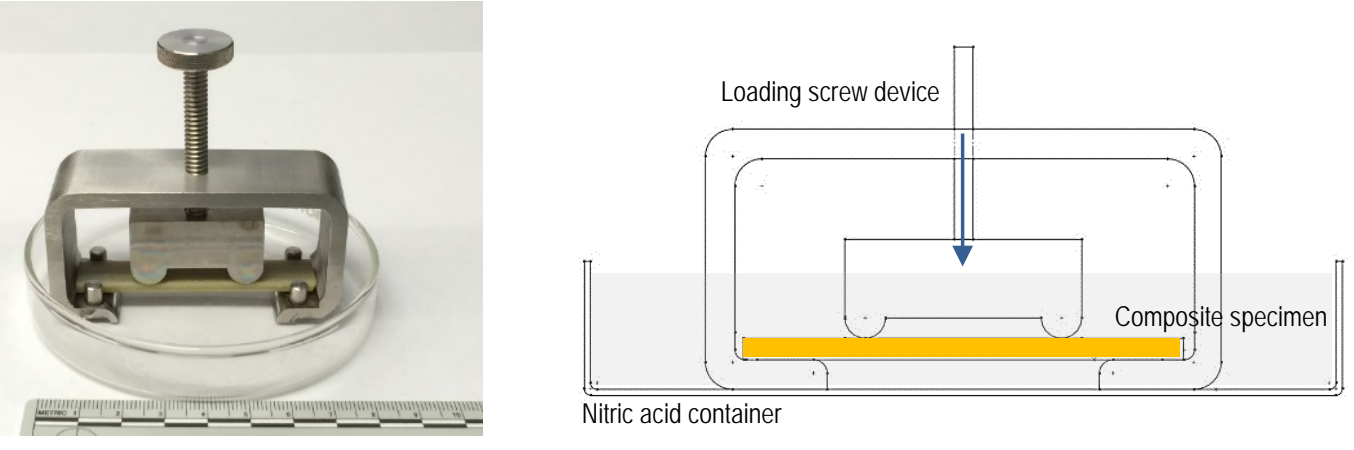

Figure 1. SCC four-point bend self-loaded fixture (left) and its schematic (right).

Six specimens for each type of composite were subjected to nitric acid solutions with either 0.063 or $0.5 \mathrm{~N}$ concentrations with three different stress levels: 0,134 and 270 
MPa. The exposure time was 72 hours and the tests were conducted at room temperature (RT), $60^{\circ} \mathrm{C}$ and $80^{\circ} \mathrm{C}$. To evaluate the scatter effect, two additional series of corrosion experiments were performed only on the E-CR 1 and E-CR 2 composites by subjecting them to the following five combinations of mechanical stresses and temperatures; 0,134 and $270 \mathrm{MPa}$ at $80^{\circ} \mathrm{C}$, and $270 \mathrm{MPa}$ at $\mathrm{RT}$ and $60^{\circ} \mathrm{C}$.

To determine the effect of fiber type on the SCC response of the composites under the most severe environmental condition considered in this research four additional specimens with E-CR 1 and E-CR 2 glass fibers were subjected to $0.5 \mathrm{~N}$ nitric acid and $270 \mathrm{MPa}$ mechanical stress at $80^{\circ} \mathrm{C}$ for periods of one month (two samples) and two months (two samples).

The sampling area in the fully submerged specimens for SCC monitoring was $800 \mathrm{~mm}^{2}$. Before the tests, the tensile sides of the specimens were imaged at specific locations to record their original surface features. A total of 48 images per specimen were collected (see Figure 2). After the corrosion tests, the specimens were taken out of the fixture, washed with distilled water and dried at room temperature. The surfaces subjected to SCC conditions were imaged again in exactly the same locations as shown in Figure 2 to determine optically and by SEM the type and extent of SCC for every test condition. In particular, stress corrosion cracks were counted for each test condition (see Figure 3). After SCC tests all un-fractured samples were subsequently subjected to three-point bend tests to determine their residual strengths and moduli at failure. 


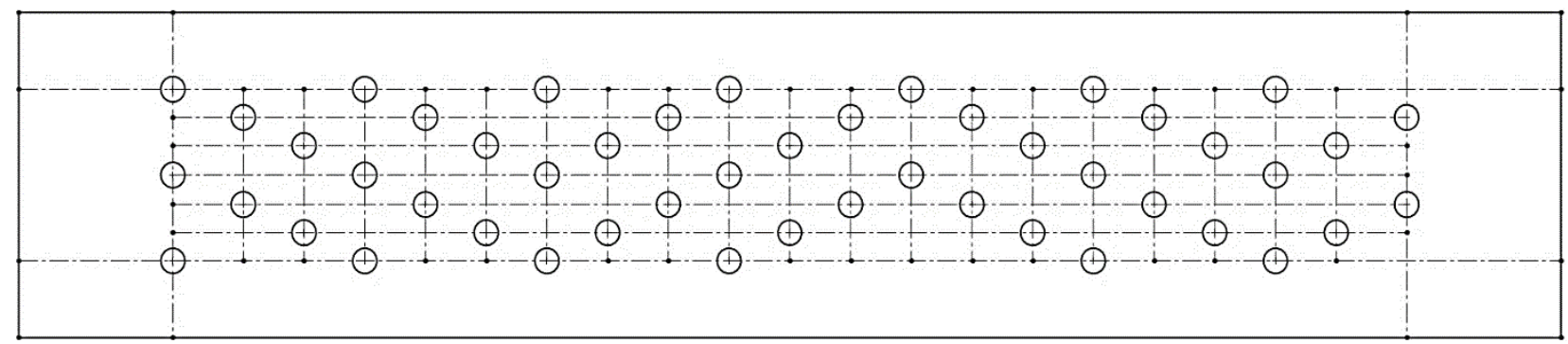

Figure 2. Locations on composite specimens selected for image analysis.
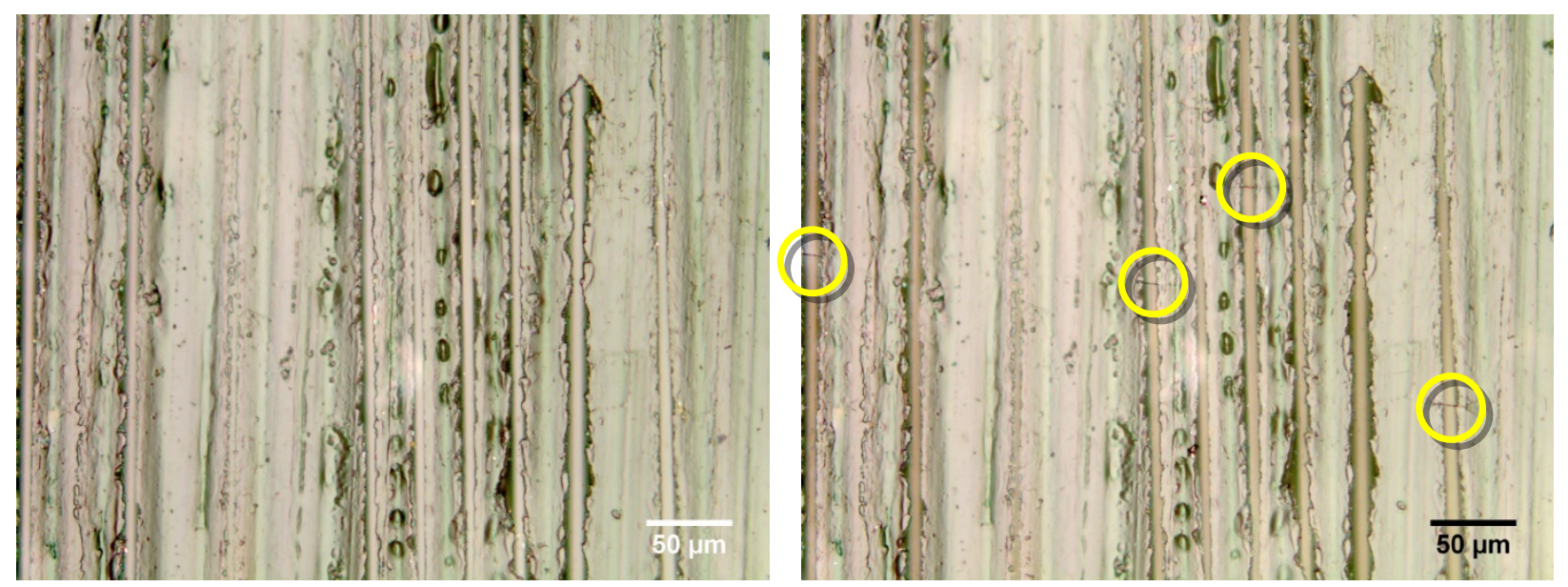

Figure 3. Surface conditions before (left) and after (right) for a SCC tested E-glass specimen subjected for 72 hours to $0.5 \mathrm{~N}$ nitric acid at $80^{\circ} \mathrm{C}$ and $134 \mathrm{MPa}$ tensile stress.

\section{Material Characterization Results}

\subsection{Surface condition and fiber characterization}

The average diameters of the fibers, amounts of surface fiber exposure and glass weight fractions for the tested composites are presented in Table 1 . The weight fractions were provided by the composite manufacturer and ranged between 75 and $80 \%$, quite typical for pultruded GRPs for transmission line applications $[13,14]$. The diameter of the E-glass fiber was much smaller than those of the E-CR fibers (see 
Figure 4). Also, the diameter of the E-CR 2 fiber was noticeably larger than the diameter of the E-CR 1 fiber.

The amount of exposed fibers on GRP composite surfaces is a very important factor greatly influencing their resistance to SCC [11]. In the case of the composites investigated in this research, the exposures listed in Table 1 are small and much smaller than what has been observed in this lab in the past [14] in older, lower quality composites manufactured by entirely different putruders. In some of these previous studies the amounts were as high as $50 \%$ for E-glass-epoxy composites. For vinylester type E-glass fiber composites, fiber exposures were found to be about 7\% [14], similar to the exposures listed in Table 1.

Table 1. Tested composites and their surface characteristics.

\begin{tabular}{llccc}
\hline Matrix & $\begin{array}{l}\text { Glass fiber } \\
\text { (unidirectional) }\end{array}$ & $\begin{array}{c}\text { Glass fiber } \\
\text { weight fraction } \\
\%\end{array}$ & $\begin{array}{c}\text { Fiber } \\
\text { diameter } \\
(\mu \mathrm{m})\end{array}$ & $\begin{array}{c}\text { Exposed fiber } \\
\text { areas } \\
\%\end{array}$ \\
\hline Vinylester-epoxy & E-glass & 75 & $12 \pm 1$ & $1.2 \pm 1.0$ \\
Vinylester-epoxy & E-CR 1 glass & 75 & $21 \pm 2$ & $2.8 \pm 2.1$ \\
Vinylester-epoxy & E-CR 2 glass & 80 & $26 \pm 3$ & $3.4 \pm 3.2$ \\
\hline
\end{tabular}

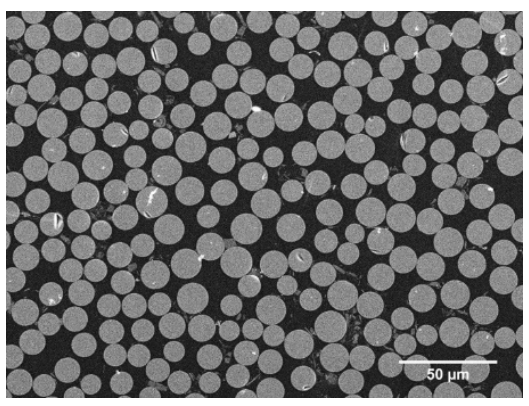

(a)

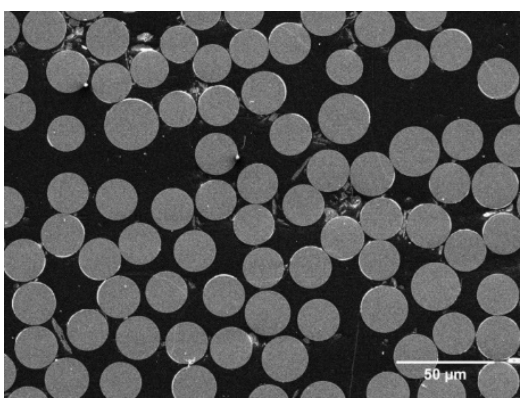

(b)

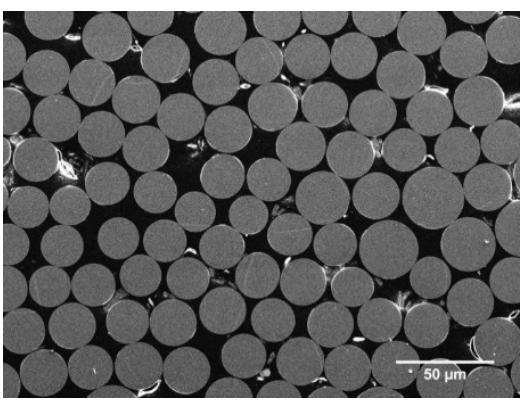

(c)

Figure 4. SEM cross-sectional images of (a) E-glass, (b) E-CR 1 glass and (c) E-CR 2 glass composites. 
3.2 Chemical compositions of glass fibers

In Table 2 chemical compositions of the E-glass and E-CR glass fibers (both types) are presented. They are compared with the compositions of typical E-glass (ASTM D57805) [40] and E-CR-glass fibers (PPG US7144836) [23, 25, 28]. The boron contents in the fibers were only able to be obtained by using the electron microprobe. The other contents, determined using both techniques, appear to be very similar for each of the three types of fibers (Table 2).

Table 2. Chemical compositions of commercially available and studied E-glass and E$\mathrm{CR}$ glass fibers under as-received conditions.

\begin{tabular}{|c|c|c|c|c|c|c|c|c|}
\hline \multirow[b]{3}{*}{ Oxide } & $\begin{array}{l}\text { Com } \\
\text { ASTM } \\
\operatorname{Ref}^{1}\end{array}$ & $\begin{array}{r}\text { nercial } \\
\text { PPG } \\
\operatorname{Ref}^{2}\end{array}$ & \multicolumn{3}{|c|}{$\begin{array}{l}\text { As-received } \\
\text { EDS } \\
\text { Analysis }\end{array}$} & \multicolumn{3}{|c|}{$\begin{array}{c}\text { As-received } \\
\text { Microprobe } \\
\text { Analysis }\end{array}$} \\
\hline & E-glass & $\begin{array}{l}\text { E-CR } \\
\text { glass }\end{array}$ & E-glass & $\begin{array}{l}\text { E-CR } 1 \\
\text { glass }\end{array}$ & $\begin{array}{l}\text { E-CR } 2 \\
\text { glass }\end{array}$ & E-glass & $\begin{array}{l}\text { E-CR } 1 \\
\text { glass }\end{array}$ & $\begin{array}{c}\text { E-CR } 2 \\
\text { Glass }\end{array}$ \\
\hline & $\%$ & $\%$ & $\%$ & $\%$ & $\%$ & $\%$ & $\%$ & $\%$ \\
\hline $\mathrm{B}_{2} \mathrm{O}_{3}$ & $0-10$ & 0 & $\Phi$ & $\Phi$ & $\Phi$ & $7.18 \pm 0.85$ & $1.07 \pm 0.18$ & $0.94 \pm 0.13$ \\
\hline $\mathrm{CaO}$ & $16-25$ & $21-26$ & $23.94 \pm 0.38$ & $21.21 \pm 0.54$ & $20.66 \pm 0.49$ & $23.40 \pm 0.03$ & $21.77 \pm 0.13$ & $23.33 \pm 0.16$ \\
\hline $\mathrm{Al}_{2} \mathrm{O}_{3}$ & $12-16$ & $10-14$ & $15.27 \pm 0.43$ & $13.18 \pm 0.38$ & $14.00 \pm 0.35$ & $13.77 \pm 0.08$ & $12.80 \pm 0.41$ & $13.99 \pm 0.13$ \\
\hline $\mathrm{SiO}_{2}$ & $52-62$ & 55-59 & $58.28 \pm 0.73$ & $60.92 \pm 0.87$ & $64.17 \pm 0.81$ & $55.77 \pm 0.26$ & $60.22 \pm 0.92$ & $60.72 \pm 0.60$ \\
\hline $\mathrm{MgO}$ & $0-5$ & $1-3.25$ & $0.56 \pm 0.22$ & $2.82 \pm 0.21$ & $0.61 \pm 0.16$ & $0.50 \pm 0.02$ & $2.79 \pm 0.05$ & $0.86 \pm 0.01$ \\
\hline $\mathrm{Na}_{2} \mathrm{O}$ & $0-2$ & $0-2$ & $1.05 \pm 0.32$ & $0.90 \pm 0.20$ & $0.13 \pm 0.17$ & $0.84 \pm 0.20$ & $0.68 \pm 0.06$ & $0.14 \pm 0.02$ \\
\hline $\mathrm{TiO}_{2}$ & $0-1.5$ & $0-1.75$ & $0.49 \pm 0.17$ & $0.91 \pm 0.43$ & $0.29 \pm 0.38$ & $0.52 \pm 0$ & $0.55 \pm 0.01$ & $0.35 \pm 0.01$ \\
\hline $\mathrm{Fe}_{2} \mathrm{O}_{3}$ & $0.05-0.8$ & $0-0.5$ & $0.27 \pm 0.16$ & $0.06 \pm 0.87$ & $0.14 \pm 0.80$ & $0.36 \pm 0.03$ & $0.23 \pm 0.01$ & $0.35 \pm 0.02$ \\
\hline ZnO & 0 & 50.5 & $0.14 \pm 0.13$ & 0 & 0 & 0 & 0 & 0 \\
\hline $\mathrm{Li}_{2} \mathrm{O}$ & - & $0.25-1.25$ & 0 & 0 & 0 & 0 & 0 & 0 \\
\hline $\mathrm{K}_{2} \mathrm{O}$ & - & - & 0 & 0 & 0 & 0 & 0 & 0 \\
\hline $\begin{array}{r}\Phi \\
\operatorname{Ref}^{1} \\
\operatorname{Ref}^{2}\end{array}$ & $\begin{array}{l}\text { Undetect } \\
\text { Standard } \\
\text { PPG US7 }\end{array}$ & $\begin{array}{l}\text { ecificatio } \\
4836\end{array}$ & 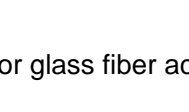 & rding ASTM & 78-05 & & & \\
\hline
\end{tabular}

The average oxide contents for the E-glass fibers fall within the standard range. The main distinction found between the two E-CR glass fibers was that the average oxide contents for E-CR 1 is in better agreement with the commercial reference than for E-CR 
2. The E-CR 2 glass fibers showed a lower percentage in the content of MgO compared to the E-CR 1 glass fibers. $\mathrm{Li}_{2} \mathrm{O}$ and $\mathrm{ZnO}$ contents are negligible for both $\mathrm{E}-\mathrm{CR}$ glass fibers, and the rests of oxides are close to the commercial specifications.

\subsection{Flexural properties of as-received composites}

Figure 5 shows a set of representative flexural stress vs. strain curves for the three tested composites. The variations between the curves are relatively small indicating good and consistent overall mechanical properties of the materials. This is illustrated in Table 3, where the flexural strengths and the flexural moduli are shown with their associated scatters. It can be seen that the flexural properties are proportional to the glass content especially in the case of the moduli, which were the highest for the E-CR 2 fiber composite (see Table 1).



Figure 5. Typical examples of flexural stress vs. strain curves of the as supplied composites. 
Table 3. Flexural strengths and moduli of as received composites.

\begin{tabular}{lccc}
\hline Matrix & $\begin{array}{c}\text { Glass fiber } \\
\text { (unidirectional) }\end{array}$ & $\begin{array}{c}\text { Flexural Strength } \\
\mathbf{M P a}\end{array}$ & $\begin{array}{c}\text { Flexural Modulus } \\
\text { GPa }\end{array}$ \\
\hline Vinylester-epoxy & E-glass & $1214 \pm 10$ & $42.7 \pm 0.5$ \\
Vinylester-epoxy & E-CR 1 glass & $1156 \pm 28$ & $43.0 \pm 0.9$ \\
Vinylester-epoxy & E-CR 2 glass & $1264 \pm 19$ & $52.1 \pm 0.6$ \\
\hline
\end{tabular}

\section{Stress Corrosion Results and their Preliminary Evaluation}

\subsection{Optical and SEM observations}

Representative macro-images of SCC morphologies in the E-glass and E-CR glass composites are presented in Figures 6a-c. As expected, the E-glass fiber based composite exhibited the worst resistance to SCC; see Figures 6-9 and Table 4a. SCC was especially extensive on the surfaces of the samples tested at high temperatures under large bending stresses (see Figure 6a). Individual, relatively short surface cracks, crack interactions, and the final macro-failure cracks, so typical for this type of failure process in E-glass polymer composites [11-14], are all visible in Figure 6a. The extent of the SCC damage on the composite surfaces was directly related to the test temperature and the magnitude of the applied stress and acid concentration, with temperature playing a significantly stronger role in the failure process than mechanical stress. 


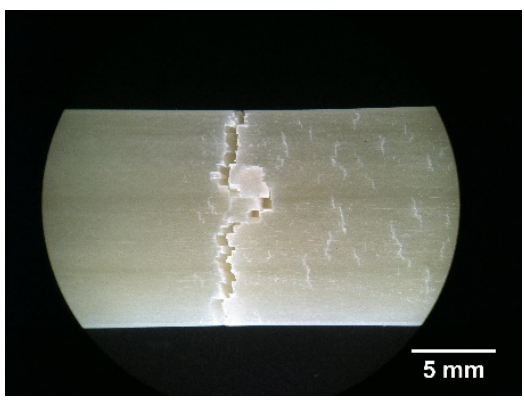

(a)

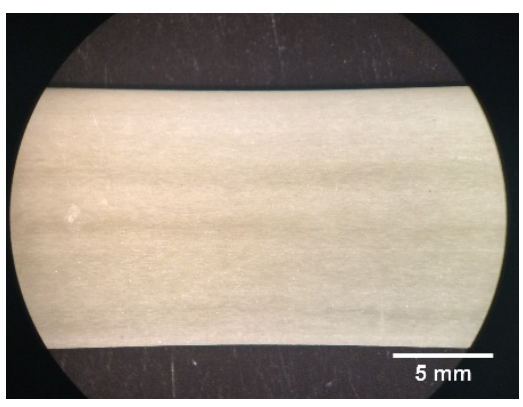

(b)

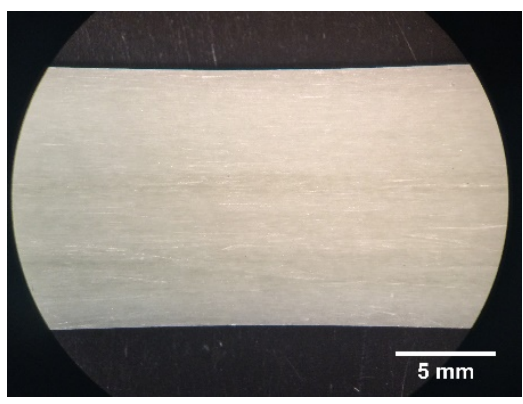

(c)

Figure 6. Optical images of samples exposed to $0.063 \mathrm{~N}$ acid at $80^{\circ} \mathrm{C}$ and $134 \mathrm{MPa}$ stress after 72 hours for (a) E-glass, (b) E-CR 1 glass and (c) E-CR 2 glass composites.

At higher magnifications individual fiber fractures can be observed on the surfaces of the exposed E-glass fibers (Figure 7). No visible SCC was detected on the unexposed fiber surfaces covered by the matrix, supporting one of the main conclusions in Refs. $[11,14]$. As can be seen in Figures 7 and 8 , the SCC process initiates on the surfaces of individual exposed E-glass fibers and then expands into the surrounding fibers developing large macroscopic cracks growing perpendicular to the direction of the applied load.
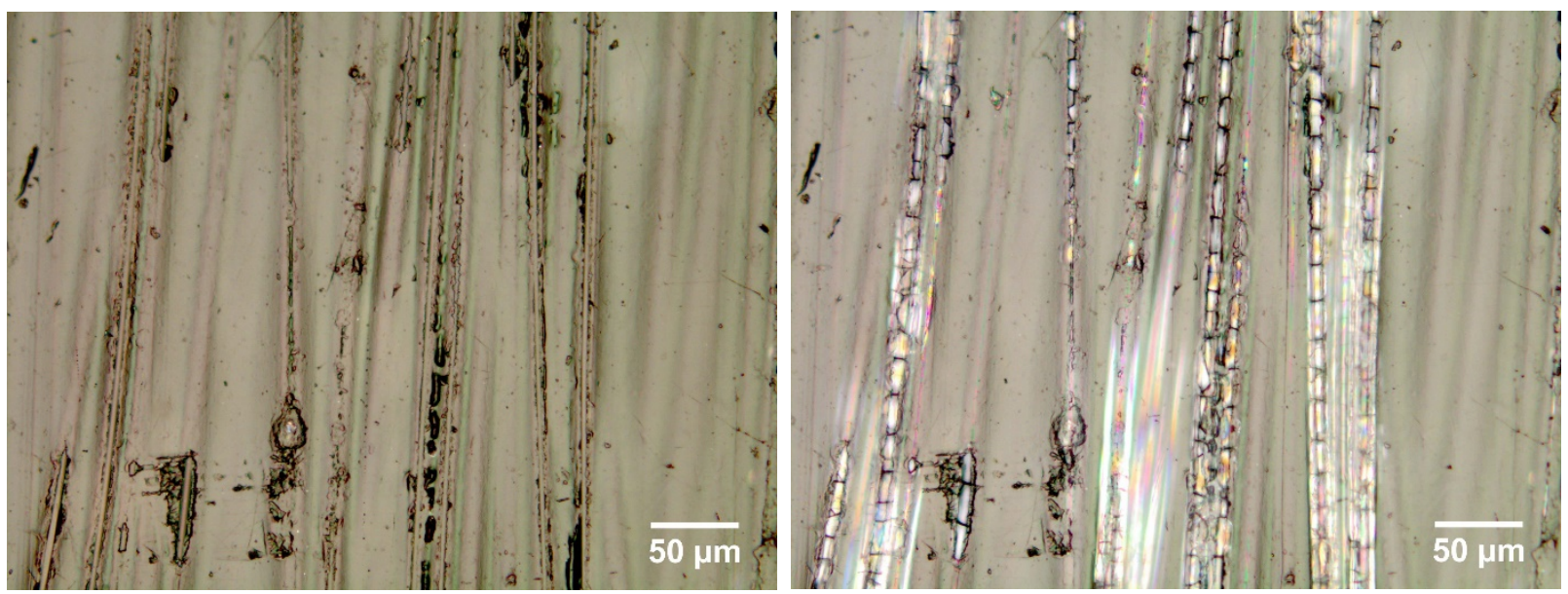
(a)

(b)

Figure 7. Optical images of SCC on E-glass composite surface before (a) and after (b) the 72 hour test in $0.063 \mathrm{~N}$ acid at $60^{\circ} \mathrm{C}$ and $134 \mathrm{MPa}$ stress.

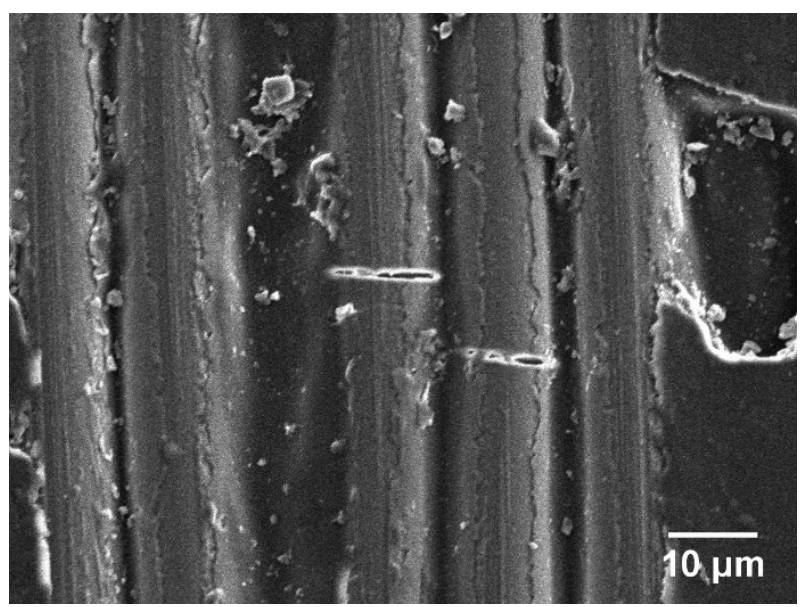

(a)

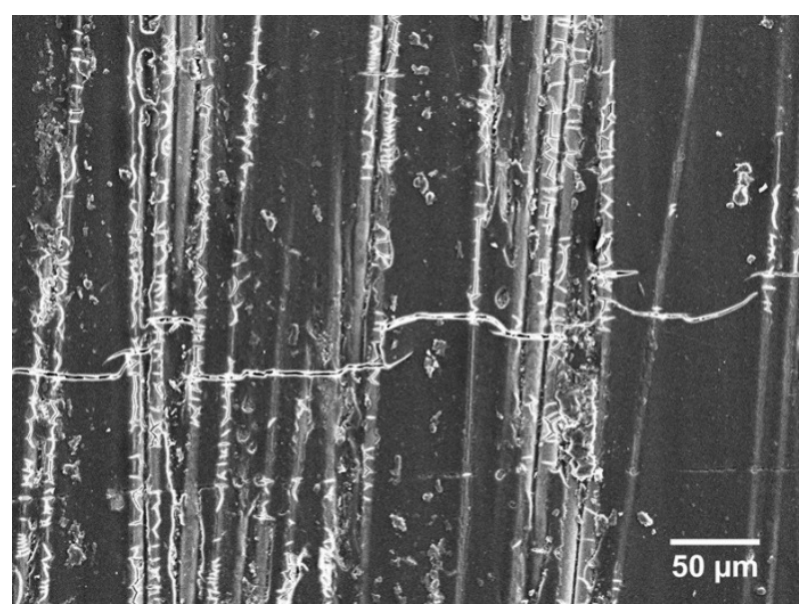

(b)

Figure 8. Representative SEM micrographs of SCC on E- glass fibers after 72 hour exposure to $0.063 \mathrm{~N}$ acid at $80^{\circ} \mathrm{C}$ and $270 \mathrm{MPa}$ stress; (a) individual cracks and (b) crack interactions.

When exposed to severe corrosion, E-glass fibers after initial failure by SCC develop complex damage zones less tied to mechanical stress with the leaching of metallic ions and residual stresses from glass fiber extrusion being the major cause [7]. The leaching creates numerous secondary axial, hoop and cylindrical cracks in the fibers. This type of post failure process, very typical for E-glass fibers subjected to acids even in the absence of external mechanical stresses, can be observed in Figure 9.

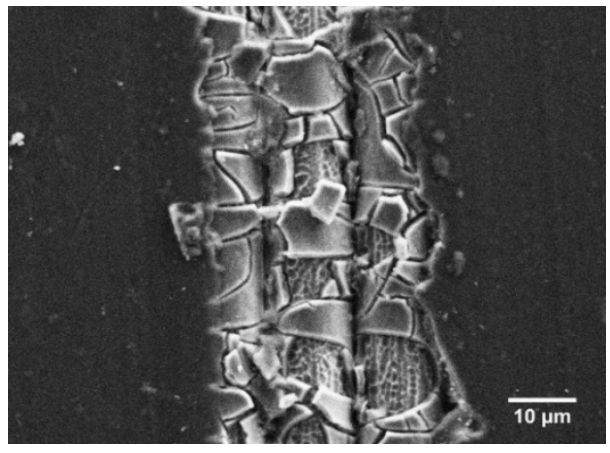

Figure 9. Typical post failure degradation of E- glass fiber exposed to $0.063 \mathrm{~N}$ acid at $80^{\circ} \mathrm{C}$ and $270 \mathrm{MPa}$ stress after 72 hours. 
In comparison with the E-glass composite, the E-CR fiber based composites showed a dramatically higher resistance to SCC under all considered environmental test conditions. However, small amounts of SCC damage in individual E-CR fibers after 72 hours were detected (Figure 10). The intensity of the damage increased with acid concentration, temperature and stress. The damage was also noticeably more extensive in the E-CR 2 fibers than in the E-CR 1 fibers (Figure 10). The type of cracking appears to be similar to the initial stages of SCC in typical unidirectional Eglass fiber composites, usually associated with the formation of short single fiber cracks randomly distributed on the surfaces of composites. However, no crack extensions into the surrounding fibers were observed in the E-CR fiber composites.

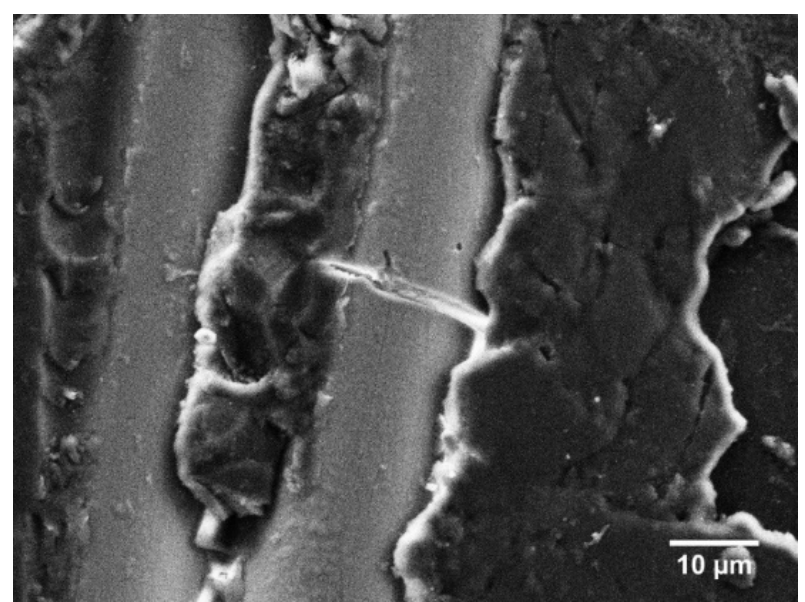

(a)

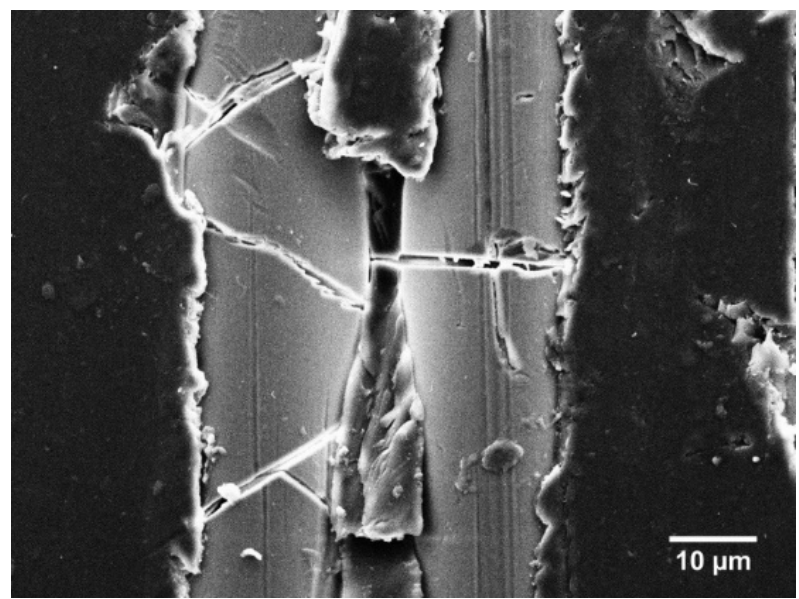

(b)

Figure 10. Representative SEM micrographs of cracking on E-CR glass fibers after exposure to $0.5 \mathrm{~N}$ acid at $80^{\circ} \mathrm{C}$ and $270 \mathrm{MPa}$; (a) E-CR 1 glass and (b) E-CR 2 glass.

\subsection{Effects of mechanical load, temperature and acid concentration}

Tables $4 a$ lists the number of stress corrosion cracks visually detected using an optical microscope on composite surfaces as a function of temperature, applied stress and acid 
concentration. For preliminary comparison between the three composites and their responses to different test conditions only one data point is shown for each composite and each corrosive environment. For the E-glass samples, increases in stress, temperature and acid concentrations generally led to an increase in the number of cracks. Samples tested at 60 and $80{ }^{\circ} \mathrm{C}$ under zero stress and at $60{ }^{\circ} \mathrm{C}$ with $134 \mathrm{MPa}$ stress in $0.063 \mathrm{~N}$ acid developed so much surface damage that counting individual fiber cracks was impossible. This is noted in Table $4 \mathrm{a}$ as too "many" cracks to count. However, those samples did not fail catastrophically contrary to the specimens tested at $80^{\circ} \mathrm{C}$ under $134 \mathrm{MPa}$, and at $\mathrm{RT}, 60^{\circ} \mathrm{C}$ and $80^{\circ} \mathrm{C}$ under $270 \mathrm{MPa}$. In these four cases catastrophic failures were detected in less than 72 hours. Considering the outcomes of the $0.063 \mathrm{~N}$ acid testing for the E-glass composite, no SCC tests were conducted for this particular composite in $0.5 \mathrm{~N}$ acid.

None of the E-CR based samples failed catastrophically for any of the testing conditions in less than 72 hours. In addition noticeably more cracks were observed in the E-CR 2 fiber composites than in the E-CR 1 type material. In both cases more cracks were observed at higher temperatures, in stronger acids and under higher stress. It was also noticed that in both cases SCC was possible even in the absence of mechanical externally applied stresses. It has been shown in [11-14] that residual manufacturing stresses in GRP are high enough to in initiate SCC in the absence of external stresses, which also happed in the composites tested in this project. 
Table 4a. Number of stress corrosion cracks on surfaces of E-glass and E-CR glass composite specimens as a function of acid concentration, temperature and mechanical stress.

\begin{tabular}{|c|c|c|c|c|c|c|c|c|c|}
\hline \multirow{3}{*}{$\begin{array}{c}\text { Applied } \\
\text { Stress } \\
\text { MPa }\end{array}$} & \multicolumn{3}{|c|}{ E-alass / VE } & \multicolumn{3}{|c|}{ E-CR 1 glass / VE } & \multicolumn{3}{|c|}{ E-CR 2 alass / VE } \\
\hline & \multicolumn{3}{|c|}{ Temperature $^{\circ} \mathrm{C}$} & \multicolumn{3}{|c|}{ Temperature $^{\circ} \mathrm{C}$} & \multicolumn{3}{|c|}{ Temperature $^{\circ} \mathrm{C}$} \\
\hline & RT & 60 & 80 & RT & 60 & 80 & RT & 60 & 80 \\
\hline \multicolumn{10}{|c|}{$0.063 \mathrm{~N}$ solution } \\
\hline 0 & 7 & Many & Many & 0 & 4 & 16 & 0 & 5 & 45 \\
\hline 134 & 34 & Many & Failed & 1 & 26 & 43 & 3 & 16 & 61 \\
\hline 270 & Failed & Failed & Failed & 22 & 15 & 47 & 20 & 47 & 92 \\
\hline \multicolumn{10}{|c|}{$0.5 \mathrm{~N}$ solution } \\
\hline 0 & N/A & $\mathrm{N} / \mathrm{A}$ & $\mathrm{N} / \mathrm{A}$ & 3 & 26 & 81 & 3 & 46 & 54 \\
\hline 134 & N/A & N/A & N/A & 8 & 30 & 45 & 12 & 41 & 65 \\
\hline 270 & N/A & N/A & $\mathrm{N} / \mathrm{A}$ & 18 & 13 & 87 & 38 & 81 & 97 \\
\hline
\end{tabular}

Many = Number of cracks greater than 150

Failed = Catastrophically failed specimens

N/A = No tests conducted

The results from the additional tests at $80^{\circ} \mathrm{C}$ (with 0,134 and $270 \mathrm{MPa}$ ) and at RT and $60^{\circ} \mathrm{C}$ with $270 \mathrm{MPa}$, market in red in Table $4 \mathrm{a}$, are shown in Table $4 \mathrm{~b}$, where the scatter effect can be observed between three specimens tested under the same conditions for one composite. Despite noticeable scatters all specimens behaved in very similar fashions in response to the corrosive conditions. In all cases higher temperatures and higher mechanical stresses resulted in more cracking for both composites. It can also be observed that the standard deviations in Table $4 \mathrm{~b}$ are slightly lower for the E-CR 2 composites excepted for the most severe aging conditions (270MPa at $80^{\circ} \mathrm{C}$ ) compared to E-CR 1 composites. 
Table 4b. Number of stress corrosion cracks on surfaces of E-CR glass composite specimens subjected to $0.5 \mathrm{~N}$ acid at $80^{\circ} \mathrm{C}$, and 0,134 and $270 \mathrm{MPa}$. Three samples for each set of conditions were tested. The data also include for comparison the numbers from Table $4 a$.

\begin{tabular}{|c|c|c|c|c|c|c|}
\hline \multirow{2}{*}{$\begin{array}{c}\text { Applied } \\
\text { Stress } \\
\text { MPa }\end{array}$} & & ₹ 1 glass & & & \multicolumn{2}{|c|}{ Temperature ${ }^{\circ} \mathrm{C}$} \\
\hline & RT & 60 & 80 & RT & 60 & 80 \\
\hline $0.5 \mathrm{~N}$ solutic & & & & & & \\
\hline 0 & 3 & 26 & $45 \pm 31$ & 3 & 46 & $46 \pm 8$ \\
\hline 134 & 8 & 30 & $48 \pm 12$ & 12 & 41 & $73 \pm 8$ \\
\hline 270 & $38 \pm 18$ & $32 \pm 37$ & $103 \pm 24$ & $38 \pm 8$ & $74 \pm 10$ & $126 \pm 34$ \\
\hline
\end{tabular}

\subsection{Residual strength and stiffness data}

Normalized residual flexural strengths and moduli for the SCC tested macroscopically un-fractured specimens are listed in Tables $5 a$ and $5 b$, and in Tables $6 a$ and $6 b$, respectively, as a function of temperature, acid concentration and stress. Similar to the number of cracks shown in Tables $4 a$ and $4 b$, we independently illustrated the effects of corrosion on strengths and moduli of individual composite samples under all conditions (Tables $5 \mathrm{a}$ and $6 \mathrm{a}$ ) and between three samples of the same composite subjected to the same selected conditions (Table $5 b$ and $6 b$ ). The data were normalized with respect to the properties measured for the as supplied samples.

The SCC effect on the residual properties of the composites is clearly visible, especially in the case of the E-glass fiber composites, gradually increasing with temperature, acid concentration and stress. Since several E-glass fiber samples either failed in less than 72 hours or were untested for the stronger acid, the residual property effect could not be 
demonstrated as well in Table $5 a$ for the E-glass samples. We can only assume that under less severe conditions (less time, lower stress and weaker acid) the effect would be much stronger for the E-glass than the E-CR glass composites.

Table 5a. Residual flexural strength (\% of original) of three tested composites after 72 hours; one sample per composite and condition.

\begin{tabular}{|c|c|c|c|c|c|c|c|c|c|}
\hline \multirow{3}{*}{$\begin{array}{c}\text { Applied } \\
\text { Stress } \\
\mathrm{MPa}\end{array}$} & \multicolumn{3}{|c|}{ E-qlass / VE } & \multicolumn{3}{|c|}{ E-CR 1 qlass / VE } & \multicolumn{3}{|c|}{ E-CR 2 qlass I VE } \\
\hline & \multicolumn{3}{|c|}{ Temperature ${ }^{\circ} \mathrm{C}$} & \multicolumn{3}{|c|}{ Temperature ${ }^{\circ} \mathrm{C}$} & \multicolumn{3}{|c|}{ Temperature ${ }^{\circ} \mathrm{C}$} \\
\hline & RT & 60 & 80 & RT & 60 & 80 & RT & 60 & 80 \\
\hline \multicolumn{10}{|c|}{$0.063 \mathrm{~N}$ solution } \\
\hline 0 & 99.2 & 100.7 & 97.4 & 99.2 & 97.8 & 100.7 & 98.8 & 97.5 & 96.5 \\
\hline 134 & 96.1 & 97.3 & Failed & 102.2 & 102.2 & 99.9 & 99.0 & 98.1 & 94.8 \\
\hline 270 & Failed & Failed & Failed & 100.0 & 100.3 & 101.0 & 99.8 & 95.9 & 93.5 \\
\hline
\end{tabular}

$0.5 \mathrm{~N}$ solution

\begin{tabular}{llllll|l|l|l|r|}
10 & N/A & N/A & N/A & 96.7 & 97.9 & 100.4 & 96.9 & 96.3 & 97.3 \\
134 & N/A & N/A & N/A & 99.2 & 100.8 & 100.0 & 98.3 & 96.0 & 95.6 \\
270 & N/A & N/A & N/A & 98.8 & 101.3 & 99.6 & 99.6 & 94.8 & 93.5 \\
\hline
\end{tabular}

Failed = Specimen did fail before the end of their schedule exposure period N/A $\quad=$ No tests conducted

Table 5b. Residual flexural strength (\% of original) for the E-CR 1 and E-CR 2 subjected to additional tests in $0.5 \mathrm{~N}$ nitric acid, $80^{\circ} \mathrm{C}$ and 0,134 and $270 \mathrm{MPa}$ stress for 72 hours. The data from Table $5 \mathrm{a}$ are also included for comparison.

\begin{tabular}{|c|c|c|c|c|c|c|}
\hline \multirow{2}{*}{$\begin{array}{c}\text { Applied } \\
\text { Stress } \\
\text { MPa }\end{array}$} & \multicolumn{3}{|c|}{ Temperature ${ }^{\circ} \mathrm{C}$} & \multicolumn{3}{|c|}{ Temperature $^{\circ} \mathrm{C}$} \\
\hline & RT & 60 & 80 & RT & 60 & 80 \\
\hline $0.5 \mathrm{~N}$ solutio & & & & & & \\
\hline 0 & 96.7 & 97.6 & $96.5 \pm 4$ & 96.9 & 96.3 & $98.1 \pm 3$ \\
\hline 134 & 99.2 & 100.8 & $96.6 \pm 3$ & 98.3 & 96.0 & $94.2 \pm 4$ \\
\hline 270 & $95.3 \pm 7$ & $98.6 \pm 3$ & $93.7 \pm 5$ & $98.0 \pm 4$ & $94.9 \pm 2$ & $94.9 \pm 3$ \\
\hline
\end{tabular}


Table 6a. Residual flexural modulus (\% of original) of three tested composites after 72 hours; one sample per composite and condition.

\begin{tabular}{|c|c|c|c|c|c|c|c|c|c|}
\hline \multirow{3}{*}{$\begin{array}{c}\text { Applied } \\
\text { Stress } \\
\text { MPa }\end{array}$} & \multicolumn{3}{|c|}{ E-glass / VE } & \multicolumn{3}{|c|}{ E-CR 1 glass / VE } & \multicolumn{3}{|c|}{ E-CR 2 glass / VE } \\
\hline & \multicolumn{3}{|c|}{ Temperature ${ }^{\circ} \mathrm{C}$} & \multicolumn{3}{|c|}{ Temperature ${ }^{\circ} \mathrm{C}$} & \multicolumn{3}{|c|}{ Temperature ${ }^{\circ} \mathrm{C}$} \\
\hline & RT & 60 & 80 & RT & 60 & 80 & RT & 60 & 80 \\
\hline \multicolumn{10}{|c|}{$0.063 \mathrm{~N}$ solution } \\
\hline 0 & 99.3 & 99.9 & 98.7 & 99.2 & 99.3 & 98.7 & 97.8 & 97.1 & 98.2 \\
\hline 134 & 94.2 & 93.9 & Failed & 104.0 & 102.3 & 97.7 & 100.2 & 96.9 & 96.8 \\
\hline 270 & Failed & Failed & Failed & 99.8 & 101.3 & 101.2 & 100.4 & 98.9 & 95.0 \\
\hline \multicolumn{10}{|c|}{$0.5 \mathrm{~N}$ solution } \\
\hline 0 & $N / A$ & $\mathrm{~N} / \mathrm{A}$ & N/A & 99.6 & 101.3 & 98.9 & 97.6 & 97.0 & 98.9 \\
\hline 134 & N/A & N/A & $N / A$ & 100.5 & 100.9 & 103.1 & 99.9 & 98.1 & 99.6 \\
\hline 270 & N/A & N/A & $\mathrm{N} / \mathrm{A}$ & \begin{tabular}{|l|}
103.1 \\
\end{tabular} & 98.8 & 98.5 & 97.7 & 98.0 & 93.6 \\
\hline
\end{tabular}

Failed = Specimen did fail before the end of their schedule exposure period N/A = No tests conducted

Table 6b. Residual flexural modulus (\% of original) for the E-CR 1 and E-CR 2 subjected to add additional tests in $0.5 \mathrm{~N}$ nitric acid, $80 \mathrm{C}$ and 0,134 and $270 \mathrm{MPa}$ stress for 72 hours. The data from Table $5 a$ are also included for comparison.

\begin{tabular}{|c|c|c|c|c|c|c|}
\hline \multirow{2}{*}{$\begin{array}{c}\text { Applied } \\
\text { Stress } \\
\text { MPa }\end{array}$} & \multicolumn{3}{|c|}{ Temperature $^{\circ} \mathrm{C}$} & \multicolumn{3}{|c|}{ Temperature $^{\circ} \mathrm{C}$} \\
\hline & RT & 60 & 80 & RT & 60 & 80 \\
\hline $0.5 \mathrm{~N}$ solutic & & & & & & \\
\hline 0 & 99.6 & 101.3 & $99.6 \pm 3$ & 97.6 & 97.0 & $101.1 \pm 3$ \\
\hline 134 & 100.5 & 100.9 & $102.1 \pm 3$ & 99.9 & 98.1 & $96.8 \pm 3$ \\
\hline 270 & $105.7 \pm 8$ & $105.5 \pm 6$ & $100.1 \pm 4$ & $97.3 \pm 3$ & $96.9 \pm 3$ & $93.0 \pm 6$ \\
\hline
\end{tabular}

Since the data in Tables $5 b$ and $6 b$ were normalized with respect to the average values shown in Table 3 , already affected by about $2 \%$ scatter, some of the residual values appear to be deceptively illogical (higher than 100\%). This should be disregarded. Most 
importantly, no clear difference between the residual strengths for the two composites were observed for the worst condition $\left(80^{\circ} \mathrm{C}\right.$ and $\left.270 \mathrm{MPa}\right)$ after 72 hours. Both of them lost about $5-6 \%$ of their strength. On the other hand, the effect of SCC on their residual moduli was significantly more visible in the case of the ECR- 2 composite ( $7 \%$ reduction) with no measurable reduction observed in its flexural modulus measurements for the ECR-1 fiber composite. The overall scatters in the residual strength and modulus measurements were relatively small, ranging from 3 to $6 \%$.

\subsection{Long term SCC testing}

After two months of testing, the E-CR 1 and E-CR 2 composite samples developed severe pitting corrosion in the fibers and more single fiber cracks (Figures 11-14), and the effect of corrosion on the fibers was noticeably stronger in the E-CR 2 fiber sample. Severe damage to the fiber/matrix interfaces and extensive delamination was also observed in both composites. Most importantly neither of the samples failed catastrophically during testing. After the tests, the surfaces of the samples were examined and their residual mechanical properties were determined by three point bending.

As can be seen in Table 7 , both composites lost about $50 \%$ of their strength. The flexural modulus was less reduced (about 20\%) for the E-CR 1 sample than for the ECR 2 composite (about 40\%). Since the number of stress corrosion cracks did not increase after the initial 72 hours (Table 7), the reduction of the residual mechanical properties of the composites can only be explained in terms of severe matrix 
degradation and severe damage to the fiber/matrix interfaces illustrated in Figures 1114.

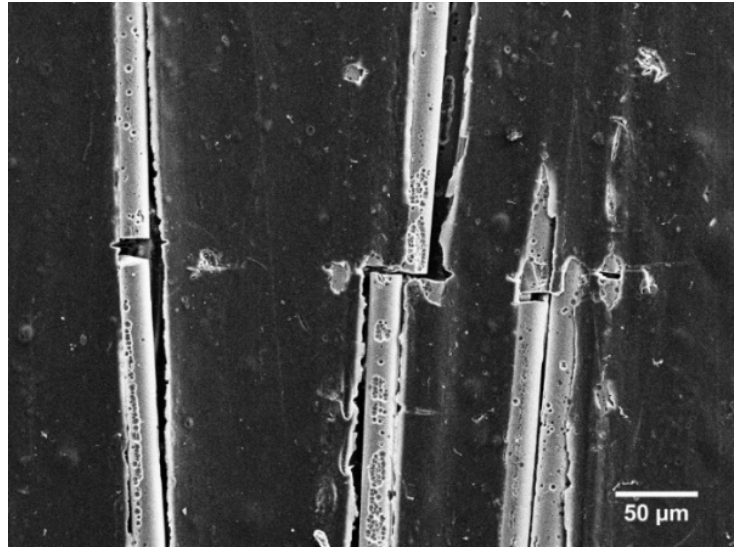

(a)

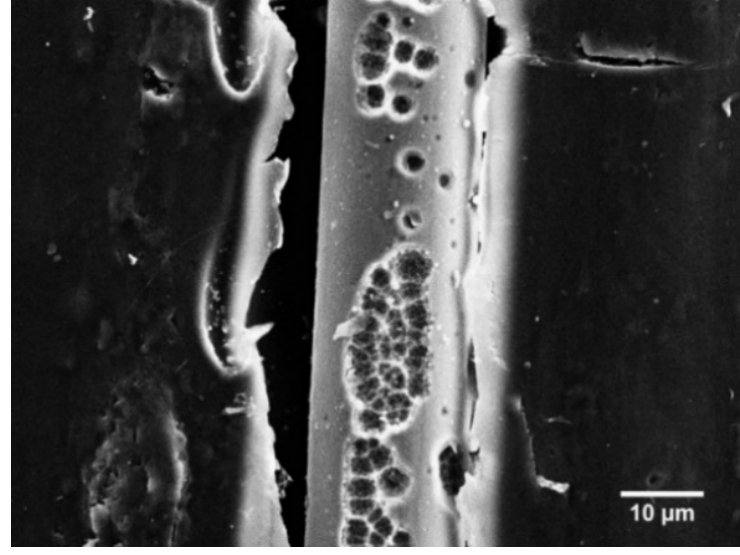

(b)

Figure 11. Individual fiber fractures, pitting fiber corrosion and interfacial damage in ECR 1 sample after two months under two different magnifications for $a$ and $b$.

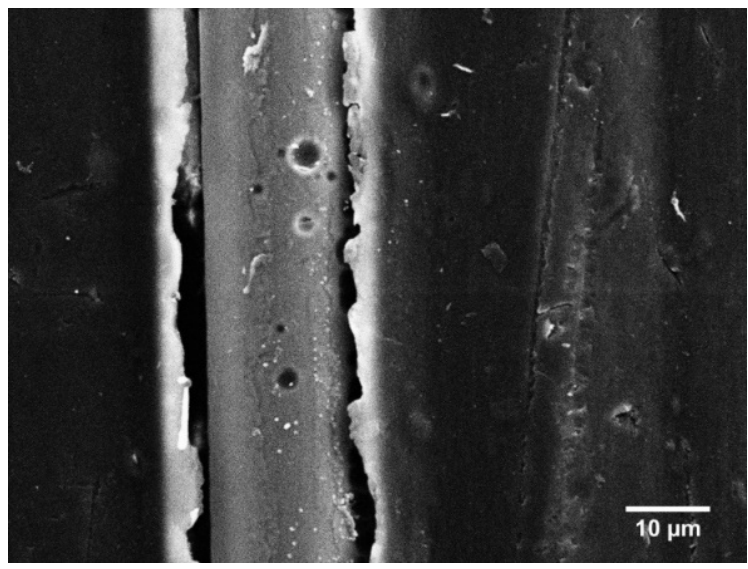

(a)

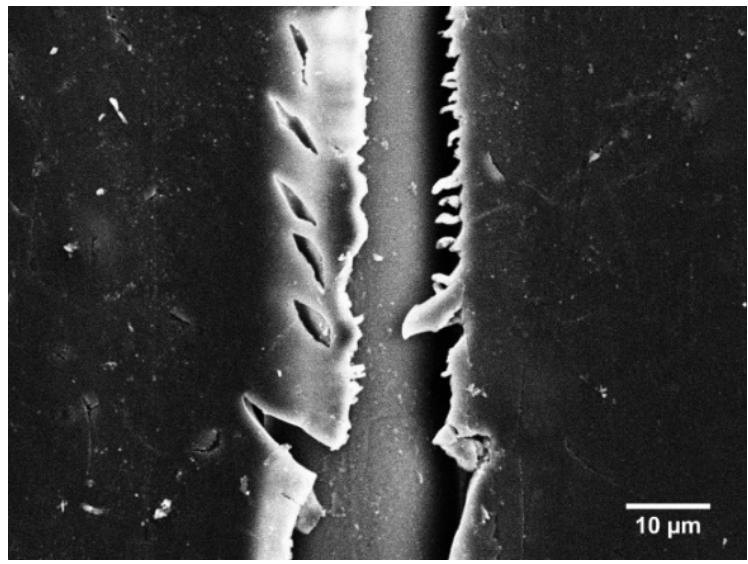

(b)

Figure 12. Examples of interfacial damage and pitting corrosion in E-CR 1 glass sample after two months. 


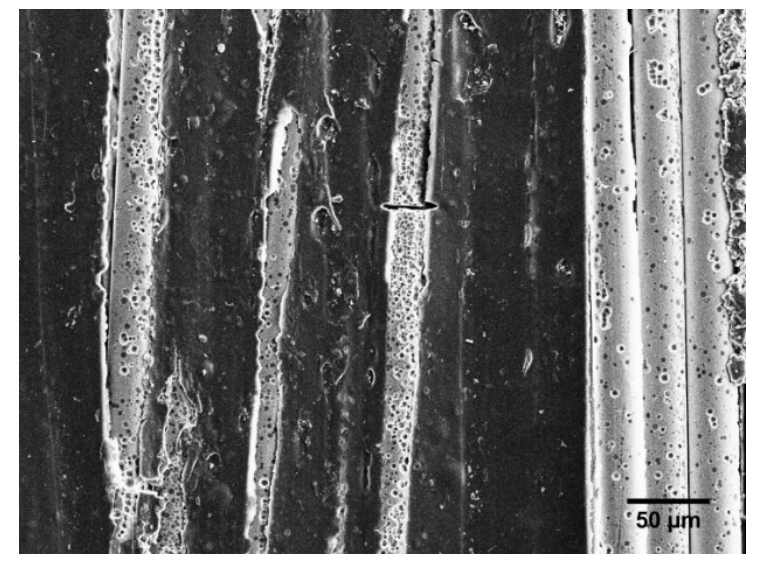

(a)

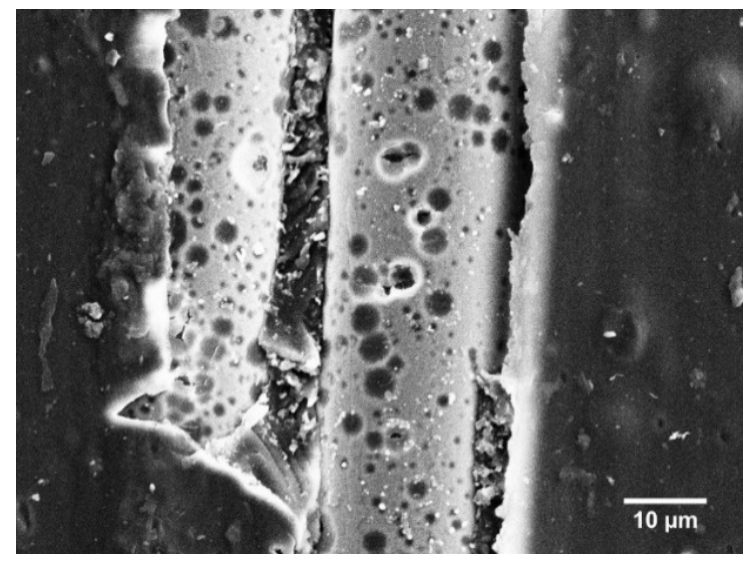

(b)

Figure 13. Examples of individual fiber fractures and pitting fiber corrosion and interracial damage in E-CR 2 sample after two months under two different magnifications for $a$ and $b$.

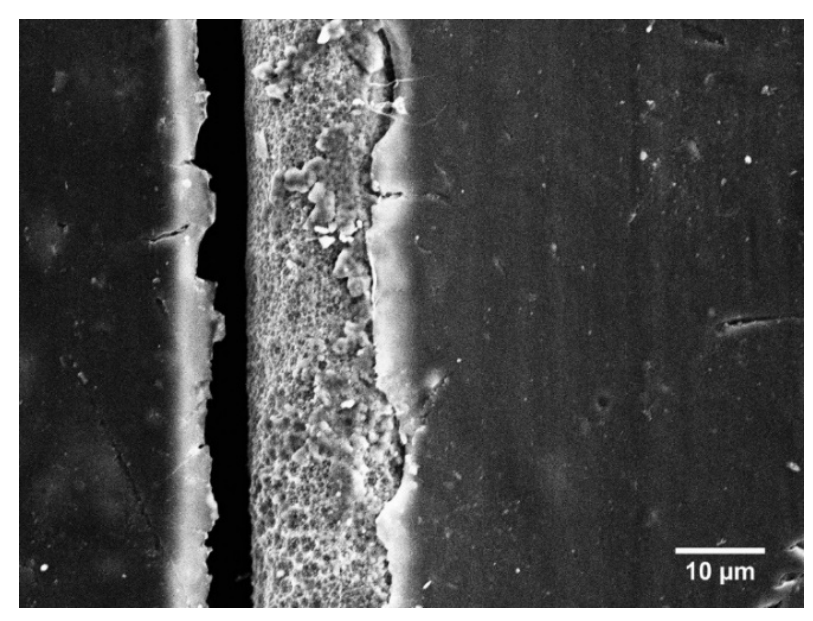

Figure 14. Pitting corrosion and interfacial damage in E-CR 2 sample after two months. 
Table 7. Number of fiber cracks, residual strength and modulus of E-CR 1 and E-CR 2 fiber composite samples subjected to $0.5 \mathrm{~N}$ nitric acid at $80^{\circ} \mathrm{C}$ and $270 \mathrm{MPa}$ stress after three different exposure times.

\begin{tabular}{c|c|c|c|c|c|c}
\hline \multirow{2}{*}{ Remark } & \multicolumn{2}{|c|}{ After 72 h* } & \multicolumn{2}{c}{ After 1 month } & \multicolumn{2}{c}{ After 2 months } \\
& $\begin{array}{c}\text { E-CR 1 } \\
\text { glass / VE }\end{array}$ & $\begin{array}{c}\text { E-CR 2 } \\
\text { glass / VE }\end{array}$ & $\begin{array}{c}\text { E-CR 1 } \\
\text { glass / VE }\end{array}$ & $\begin{array}{c}\text { E-CR 2 } \\
\text { glass / VE }\end{array}$ & $\begin{array}{c}\text { E-CR 1 } \\
\text { glass / VE }\end{array}$ & $\begin{array}{c}\text { E-CR 2 } \\
\text { glass / VE }\end{array}$ \\
\hline No. cracks & $103 \pm 24$ & $126 \pm 34$ & 102 & 125 & 93 & 109 \\
Strength & $93.7 \pm 5$ & $94.9 \pm 3$ & 89.0 & 73.2 & 54.1 & 50.4 \\
Modulus & $100.1 \pm 4$ & $93.0 \pm 6$ & 94.4 & 82.1 & 80.4 & 68.3 \\
& & & & & & \\
\hline
\end{tabular}

* Averages from three tests, see Tables 4-6.

\section{Synergistic Effects in SCC of GRP Composites}

It has been observed in this research that, as expected, there is an enormous difference in the resistance to SCC between the E-glass and E-CR glass fiber composites based on a vinylester-epoxy resin in nitric acid. Similar observations have already been made based on similar testing of very similar composites from different suppliers at room temperature $[13,14]$. In this research, the temperature component was added which further supported the past observations on the superior properties of E-CR glass/polymer composites in highly acidic corrosive environments.

Two tests were conducted under extreme conditions $\left(0.5 \mathrm{~N}\right.$ nitric acid, $80^{\circ} \mathrm{C}, 270 \mathrm{MPa}$ stress and two months of testing) to determine if E-CR glass fibers could, at some point in time, start reducing their resistance to corrosion. In essence, an attempt was made to determine the limitations of E-CR fibers under severe SCC conditions for composites which could be used in HV and other applications. It was shown that small amounts of 
SCC damage to the fibers can occur after two months without any macroscopic crack extension and macroscopic failures. Instead of catastrophic SCC sample failures, readily observed in E-glass samples even after only 3 days of testing under the same conditions, the E-CR composites failed by a gradual chemical deterioration and decomposition of the fiber/matrix interfaces, matrix degradation, extensive delaminations, and the structural failure of the composites with the fibers themselves damaged only slightly.

As reported elsewhere $[3-5,7,15,18,21,31]$, in E-glass fibers, non-silicon based ions are leached from the glass surface and replaced with hydrogen ions, which eventually leads to cracking and failure of the fibers. Li, H. et al. [28] studied the acid corrosion characteristics of E-glass fibers over the boron concentration and they found the formation of an altered layer on the fibers with severe depletion of $\mathrm{Al}, \mathrm{Ca}$ and $\mathrm{B}$. The growth of the altered layer during the acid leaching was the primary mechanism that controlled E-glass fiber corrosion.

For the E-CR fibers the oxides remained practically unaffected by long term stress corrosion even in the highly concentrated nitric acid solution at high temperature. For example, the content of $\mathrm{Al}_{2} \mathrm{O}_{3}$ in the E-CR 1 fibers went down from $13.2 \pm 0.4 \%$ to 11.1 $\pm 1.0 \%$, whereas in the E-CR 2 fibers it was reduced from $14.0 \pm 0.35 \%$ to $12.3 \pm 1.2 \%$. The contents of $\mathrm{CaO}$ were essentially unaffected by corrosion. The leaching measurements were performed along the longitudinal surfaces of the fibers exposed to corrosion. 
Under the SCC conditions of this study the combined effect of temperature and applied load was dramatic for the E-glass composite even under the low acid concentration. Only the samples tested at RT and at $60^{\circ} \mathrm{C}$ under $134 \mathrm{MPa}$ did not catastrophically fail during testing. The amount of SCC damage on the surface was much more extensive at $60^{\circ} \mathrm{C}$ than at RT. For higher stresses all samples failed catastrophically, see Figure $6 \mathrm{a}$. Catastrophic failure was also observed for the $134 \mathrm{MPa}$ stressed sample at $80^{\circ} \mathrm{C}$. Clearly the combination of temperature and stress was much more damaging to the Eglass composite than the individual effects. Therefore, it can be concluded that the synergistic effects on E-glass fiber composites were much stronger than in the case of the E-CR glass composites.

\section{Other Factors Contributing to SCC and its Monitoring}

Monitoring SCC in high quality GRPs is usually very difficult if rates of corrosion are low. Acoustic emission does not always work well if used to monitor E-CR glass fiber composites [37]. In this research visual observations were performed on optical and SEM images to determine the number of corrosion cracks with the assumption that most, if not all, corrosion cracks are located on the composite surface throughout the entire process. Significant and logical differences were observed between SCC in the composites under significantly different environmental conditions.

Some of the scatters in the number of cracks listed in Tables 4 (a) and (b) could be explaining by: (1) our assumption that all cracks are located only on the surface of the 
E-CR specimens and (2) by the effect of temperature on very likely significant stress relaxations at higher temperatures which could also be very strongly affected by the local geometrical conditions (local fiber distributions) on composite surfaces. It is possible that by monitoring the SCC process by visual observations some of the cracks initiated under the surface and covered by the matrix could have been missed by our detection process. This effect could be much stronger in the case of the E-glass fiber composite since this composite developed significantly more SCC than the E-CR fiber composites.

With regard to the temperature effect on SCC in GRPs, both physical and chemical aging processes [42-44] were certainly involved in the corrosion of all composites at elevated temperatures. For shorter periods of time (for example, for 72 hours) physical aging $[42,43]$ would be more influential increasing the stiffness of the matrix and increasing residual stresses in the matrix and the fibers. On the other hand, elevated temperatures would decrease the residual manufacturing stresses both in the matrix and the fibers reducing the rates of corrosion. Therefore, the effect of temperature on the mechanical aspects of SCC could be neutral overall unless chemical aging is involved for longer periods of time, as observed in this research (Table 7). It can be assumed that the accelerated rates of SCC with temperature up to 72 hours, observed in this research, were most likely caused by an increase in the leaching of metal ions with temperature. 
To evaluate the temperature effects on the leaching processes of metal ions out of the E-glass and both E-CR glass fibers additional tests were conducted using the EDS technique. Also, to determine the extent of the sizing effect [33], leaching of $\mathrm{CaO}$ and $\mathrm{Al}_{2} \mathrm{O}_{3}$ from the fibers was estimated from the longitudinal and transverse fiber surfaces for comparison. Six independent tests were conducted per condition. It was assumed that the leaching from the longitudinal surfaces of the fibers was affected by sizing which was obviously not present on the transverse fiber cross sections.

If we examine the data presented in Table 8, several important observations can be made. First, sizing plays a very important role at room temperature, especially in the case of the E-glass fibers with much less leaching detected along the longitudinal surfaces than along their cross sections. Second, the sizing effect is still present for the E-CR fibers at RT but is much less noticeable. Finally, at $60 \mathrm{C}^{\circ}$ and $80^{\circ} \mathrm{C}$ the sizing effect is essentially insignificant. 
Table 8. Leaching of $\mathrm{CaO}$ (a) and $\mathrm{Al}_{2} \mathrm{O}_{3}$ (b) from E-glass, E-CR 1 and $\mathrm{E}-\mathrm{CR} 2$ glass fibers as a function of temperature in $0.5 \mathrm{~N}$ nitric acid along longitudinal and perpendicular (cross-section) surfaces.

(a) $\mathrm{CaO}$

\begin{tabular}{lcccc}
\hline & As-rec'd & RT & $\mathbf{6 0}{ }^{\circ} \mathbf{C}$ & $\mathbf{8 0}{ }^{\circ} \mathbf{C}$ \\
\hline E-glass & & & & \\
Cross section & $23.94 \pm 0.38$ & $4.43 \pm 1.75$ & $0.55 \pm 0.57$ & $0.21 \pm 0.18$ \\
Longitudinal & $26.95 \pm 0.58$ & $23.25 \pm 0.50$ & $0.27 \pm 0.21$ & $0.86 \pm 0.23$ \\
& & & & \\
E-CR 1 glass & & & & \\
Cross section & $21.21 \pm 0.54$ & $21.48 \pm 0.28$ & $20.66 \pm 1.46$ & $18.71 \pm 0.04$ \\
Longitudinal & $21.68 \pm 0.74$ & $19.78 \pm 0.06$ & $21.12 \pm 0.72$ & $21.29 \pm 0.02$ \\
E-CR 2 glass & & & & \\
Cross section & $20.66 \pm 0.49$ & $23.66 \pm 0.10$ & $23.55 \pm 1.07$ & $20.46 \pm 0.17$ \\
Longitudinal & $23.08 \pm 2.14$ & $23.16 \pm 1.08$ & $22.63 \pm 0.01$ & $21.00 \pm 0.23$ \\
\hline
\end{tabular}

(b) $\mathrm{Al}_{2} \mathrm{O}_{3}$

\begin{tabular}{lcrrr}
\hline & As-rec'd & RT & $\mathbf{6 0}{ }^{\circ} \mathbf{C}$ & $\mathbf{8 0}{ }^{\circ} \mathbf{C}$ \\
\hline E-glass & & & & \\
Cross section & $15.27 \pm 0.43$ & $2.69 \pm 0.35$ & $0.94 \pm 0.79$ & $0.51 \pm 0.20$ \\
Longitudinal & $14.37 \pm 0.39$ & $14.27 \pm 0.52$ & $0.08 \pm 0.03$ & $0.99 \pm 0.33$ \\
& & & & \\
E-CR 1 glass & & & & \\
Cross section & $13.18 \pm 0.38$ & $13.41 \pm 0.30$ & $12.99 \pm 0.35$ & $10.94 \pm 0.21$ \\
Longitudinal & $13.58 \pm 0.01$ & $13.88 \pm 0.04$ & $13.39 \pm 0.04$ & $13.38 \pm 0.73$ \\
E-CR 2 glass & & & & \\
Cross section & $14.00 \pm 0.35$ & $13.66 \pm 0.15$ & $12.96 \pm 0.19$ & $12.17 \pm 0.88$ \\
Longitudinal & $13.81 \pm 0.71$ & $14.48 \pm 0.39$ & $14.53 \pm 0.03$ & $14.65 \pm 0.18$ \\
\hline
\end{tabular}

The method used in this research to monitor for the initiation of SCC in GRPs is based on visual observations and is extremely time consuming. Another method which could be used to evaluate the response of different composites to SCC, related synergistic 
effects, and other associated aging mechanisms such as general composite degradation, is based on measurements of residual strengths and moduli of GRPs affected by SCC; see Tables 5-6 (a) and (b). Depending on the type and extent of damage, SCC in unidirectional GRP composite samples can be monitored by correlating the number and type of stress corrosion cracks with such macroscopic mechanical properties as flexural strength and modulus. However, for E-glass fiber composites, even short term exposure to concentrated acids can lead to catastrophic failures which will prohibit residual property measurements. For E-CR fiber composites, despite their superior resistance to SCC, under long exposure times the aging damage to the glass/matrix interfaces and resin degradation [44] become the dominant factors responsible for the reduction in the macro-mechanical properties of the composites. In our two months aging tests on the E-CR fiber composites, there was roughly a $6 \%$ reduction in mechanical properties due to SCC with about $40 \%$ reduction due to the interface and matrix decomposition.

\section{Conclusions}

Several new observations can be made based on the data presented in this work. First, the synergistic effect of acid concentration, mechanical load and temperature was found to be much stronger on the SCC of the tested composites than the individual and double (acid plus load, or acid plus temperature) effects. This was found for both the Eglass and E-CR glass composites, but much stronger for the E-glass composites. Second, the E-CR fibers are not entirely immune to SCC in severe corrosive 
environments based on highly concentrated nitric acid solutions especially at high temperatures. They developed short individual fiber cracks, almost identical to E-glass fibers without, however, any visible crack extensions and catastrophic failures. It was also shown in this work that sizing on E-glass and E-CR glass fibers protect the fibers against leaching but only at room temperature and short periods of time. At elevated temperatures the rates of leaching of $\mathrm{Al}$ and $\mathrm{Ca}$ ions out of the fibers were essentially not affected by sizing.

It was also identified for the first time that the E-CR fiber composites subjected to extreme SCC fail by gradual degradation of their interfaces and matrices instead of catastrophic sample failures typical for E-glass fiber based GRPs. Finally, it appears, based on the residual strength and stiffness investigation performed in this project, the extent of initial SCC damage in both E-glass and E-CR glass GRPs can be estimated by measuring their strength and stiffness properties. As the process progresses, however, the accuracy of the estimation will be negatively affected by the interface/matrix aging in the case of E-CR fiber composites, and by the catastrophic failures of the E-glass GRPs under severe corrosion.

\section{Acknowledgments}

This research was supported jointly by the MacLean Power System Corporation between October 1, 2012 and June 30, 2014, and since June 2014 by the National Science Foundation Industry/University Cooperative Research Center for Novel High Voltage/High Temperature Materials and Structures under \#IIP1362135, and by the National Science Foundation Grant Opportunities for Academic Liaison with Industry program under \#CMMI-123252. The authors would also like to thank Dr. Joe Hoffman and Dr. Paul Predecki for their comments on this paper, 


\section{References}

1. Hogg P. J. Factors affecting the stress corrosion of GRP in acid environments. Composites 1983; 14 (3): 254-261.

2. Jones F. R, Rock J. W, and Wheatley A. R. Stress corrosion cracking and its implications for the long-term durability of E-glass fibre composite. Composites 1983; 14 (3): 262-269.

3. Lewis G, Bedder S. W, Reid, I. Stress corrosion of glass fibres in acidic environments. J Mater Sci Lett 1984; 3 (8): 728-732.

4. Elmer T. H. Leaching of E-Glass. J. Am. Ceram. Soc. 1984; 67 (12): 778-782.

5. Rodriguez E. L. Corrosion of glass fibers. J Mater Sci Lett 1987; 6 (6): 718-720.

6. Sapalidis S. N, Hogg P. J, Youd S. J. High temperature acidic stress corrosion of glass fibre composites: Part I Effect of fiber type. J Mater Sci 1997; 32 (2): 309316.

7. Qui Q, Kumosa M. Corrosion of E-glass fibers in acidic environments. Compos Sci Technol 1997; 57 (5): 497-507.

8. Carpenter S. H, Kumosa M. An investigation of brittle fracture of composite insulator rods in an acidic environment with either static or cyclic loading. J Mater Sci 2000; 35 (17): 4465-4476.

9. Ely $T$, Armentrout $D$, Kumosa M. Evaluation of stress corrosion properties of pultruded glass fiber/polymer composite materials. J Compos Mater 2001; 35 (9): 751-773.

10. Kawada $\mathrm{H}$, Srivastava $\mathrm{V}$. K. The effect of an acidic environment on the stressintensity factor for GRP laminates. Compos Sci Technol 2001; 61 (8): 1109-1114.

11. Kumosa L, Armentrout D, Kumosa M. An evaluation of the critical conditions for the initiations of stress corrosion cracking in unidirectional E-glass/polymer composites. Compos Sci Technol 2001; 61 (4): 615-623.

12. Megel M, Kumosa L, Ely $T$, Armentrout D, Kumosa M. Initiation of stresscorrosion cracking in unidirectional glass/polymer composite materials. Compos Sci Technol 2001; 61 (2): 231-246. 
13. Armentrout $D$, Kumosa $M$, McQuarrie T. S. Boron-free fibers for prevention of acid induced brittle fracture of composite insulator GRP rods. IEEE Transactions on Power Delivery 2003; 18 (3): 684-693.

14. Kumosa L, Kumosa M, Armentrout D. Resistance to stress corrosion cracking of unidirectional ECR-glass/polymer composites for high voltage composites insulator applications. Composites: Part A 2003; 34 (1): 1-15.

15. Jones, R. L. Betz D. The kinetics of corrosion of E-glass fibres in hydrochloric acid. J Mater Sci 2004; 39 (18): 5633-5637.

16. Kumosa M, Kumosa L, Armentrout D. Failure analyses of nonceramic insulators: Part I-Brittle fracture characteristics. IEEE Electrical Insulation Magazine 2005; 21 (3): 14-27.

17. Kumosa M, Kumosa L, Armentrout D. Failure analyses of nonceramic insulators: Part II-The brittle fracture model and failure prevention. IEEE Electrical Insulation Magazine 2005; 21 (4): 28-41.

18. Jones R. L, Stewart J. The kinetics of corrosion of e-glass fibres in sulphuric acid. J Non-Cryst Solids 2010; 356 (44-49): 2433-2436.

19. Dai J, Yao X, Liang X, Yeh H. Y. Experimental study of micro-cracks in stress corrosion of fiber reinforced composites. Polym Test 2006; 25 (6): 758-765.

20. Myers T. J, Kytomaa H. K, Smith T. R. Environmental stress-corrosion cracking of fiberglass: Lessons learned from failures in the chemical industry. J Hazard Mater 2007; 142 (3): 695-704.

21. Jones R. L. Chemical corrosion of E-glass fibers in oxalic and other organic acids. J. Am. Ceram. Soc. 2006; 89 (1): 20-23.

22. Lutz B, Cheng L, Guan Z, Wang L, Zhang F. Analysis of a fractured $500 \mathrm{kV}$ composite insulator-identification of aging mechanisms and their causes. IEEE Transactions on Dielectrics and Electrical Insulation 2012; 19 (5): 1723-1731.

23. Hartman D, Greenwood D, Miller D. M. High strength glass fibers. Technical Paper AGY 1996: 1-11.

24. Kudryavtsev M. Y, Popovich N. V, Mikhailenko N. Y, Kolesov Y. I. Modification of alkaline-free glass compositions for fiberglass production. Glass and Ceramics 2000; 57: 9-10. 
25. Wallenberger F. T, Bingham P. A. Fiberglass and Glass Technology: EnergyFriendly Compositions and Applications; Springer Science + Business Media, LLC 2010.

26. Lieser M. Glass fibre reinforcement type significantly impacts FRP corrosion performance. JEC Composites Magazine 2011; 69: 49-51.

27. Owens Corning. Glass fiber reinforcement chemical resistance guide - For the selection of glass fiber reinforcements in fiber reinforced polymer (FRP) for corrosive environments. 2011: 1-32.

28. Li H, Gu P, Watson J, Meng J. Acid corrosion resistance and mechanism of Eglass fibers: boron factor. J Mater Sci 2013; 48 (8): 3075-3087.

29. Liu J, Jiang M, Wang $Y$, Wu G, Wu Z. Tensile behaviors of ECR-glass and high strength glass fibers after $\mathrm{NaOH}$ treatment. Ceramics International 2013; 39 (8): 9173-9178.

30. Amaro A. M, Reis P. N. B, Neto M. A, Louro C. Effects of alkaline and acid solutions on glass/epoxy composites. Poly Degrad Stab 2013; 98 (4): 853-862.

31. Ramachandran B. E, Balasubramanian N. The effect of temperature on the rate of removal of ions from E-glass. J Mater Sci Lett 1985; 4 (6): 688-690.

32. Feih S, Manatpon K, Mathys Z, Gibson A. G, Mouritz A. P. Strength degradation of glass fibers at high temperatures. J Mater Sci 2009; 44 (2): 392-400.

33. Nagae $\mathrm{S}$, Otsuka Y. Effect of sizing agent on corrosion of glass fibres in water. J Mater Sci Lett 1994; 13 (20): 1482-1483.

34. Liang X, Wang J, Dai J. Surface micro-crack initiated brittle fracture in fiber reinforced plastic rod of composite insulator. IEEE transactions on Dielectrics and Electrical Insulation 2010; 17 (2): 368-374.

35. Li H, Yan M, Qi D, Zhang S, Ding N, Cai X, Li Q, Zhang X, Deng J. Corrosion of E-glass fiber in simulated oilfields environments. J Petroleum Sci Eng 2011; 78 (2): 371-375.

36. Ellyin F, Maser R. Environmental effects on the mechanical properties of glassfiber epoxy composite tubular specimens. Compos Sci Technol 2004; 64 (12): 1863-1874.

37. Kosak J. Monitoring Stress Corrosion Cracking in Polymer Matrix Composites with Acoustic Emission. MSc in Materials Science Thesis, National Science Foundation Industry/University Cooperative Research Center for Novel High 
Voltage/Temperature Materials and Structures. University of Denver, Denver CO 2014.

38. ASTM D790-10, Standard Test Method for Flexural Properties of Unreinforced and Reinforced Plastics and Electrical Insulating Materials, ASTM, West Coshohocken, PA. 2010.

39. ASTM D6272-10, Standard Test Method for Flexural Properties of Unreinforced and Reinforced Plastic and Electrical Insulating Materials by Four-Point Bending, ASTM, West Coshohocken, PA. 2010.

40. ASTM D578/D578 M-05 (Reapproved 2011), Standard Specifications for Glass Fiber Strands, ASTM West Coshohocken, PA. 2011.

41. Adams P. B. Glass corrosion. A record of the past? A prediction of the future? J Non-Cryst Solids 1984; 67 (1-3): 193-205.

42. Middleton J, Burks B, Wells T, Setters A. M, Jasiuk I, Predecki P, Hoffman $\mathrm{J}$, Kumosa $\mathrm{M}$. The effect of ozone on polymer degradation in Polymer Core Composite Conductors. Poly Degrad Stab 2013; 98 (1): 436-445.

43. Middleton J, Burks B, Wells T, Setters A. M, Jasiuk I, Kumosa M. The effect of ozone and high temperature on polymer degradation in polymer core composite conductors. Poly Degrad Stab 2013; 98 (11): 2282-2290.

44. Hoffman J, Middleton J, Kumosa M. Effect of a surface coating on flexural performance of thermally aged hybrid glass/carbon epoxy composite rods. Compos Sci Technol; 106 (16): 2015, 141-148. 